\title{
A brief smoking cessation intervention for adults in hospital was cost effective
}

\author{
Meenan RT, Stevens VJ, Hornbrook MC, et al. Cost-effectiveness of a hospital-based smoking cessation intervention. Med Care 1998 \\ May;36:670-8.
}

\section{Question}

Is an in hospital smoking cessation programme for a general population of adult patients cost effective?

\section{Design}

Cost effectiveness analysis from the perspective of the implementing hospital, using data from a controlled trial with follow up at 12 months.

\section{Setting}

Two 200 bed hospitals managed by Kaiser Permanente Northwest health maintenance organisation in Oregon and Washington, USA.

\section{Patients}

1119 patients $\geqslant 18$ years of age (mean age $44 \mathrm{y}, 62 \%$ women)* who reported smoking regularly in the previous 3 months. Patients with a hospital stay $<36$ hours as well as those who were postpartum, admitted for substance abuse, or receiving hospice care were excluded.

\section{Intervention}

453 patients were allocated to the intervention and were offered 20 minutes of bedside counselling with an experienced counsellor, a 12 minute video, self help materials, and 1-2 follow up telephone calls after discharge*. 666 patients received usual care*.

\section{Main outcome and cost measures}

Quit rates (self reported consecutive abstinence from all tobacco use); incremental quit rate (number of patients who quit in the intervention group minus number who quit in the usual care group); cost per incremental quit (incremental costs per smoker divided by incremental quit rate); and discounted life years saved (DLYS). Life years saved were estimated from published data on smoking related changes in life expectancy. Total intervention costs included costs to identify newly admitted smokers, solicit cooperation, deliver bedside counselling, and follow up after discharge. All costs were reported in 1994 US dollars.

\section{Main results}

Analysis was by intention to treat. At 12 months, patients who received the smoking cessation intervention had higher quit rates than patients who received usual care $(\mathrm{p}=0.02)$ (table). The cost per incremental quit was US $\$ 3697$. At a $5 \%$ discount rate and an incremental quit rate of $4.3 \%$, the cost per DLYS was $\$ 3680$, which compares favourably with other well accepted healthcare interventions. Sensitivity analysis found incremental costs per incremental DLYS ranging from $\$ 909$ to $\$ 53347$ when the quit rate was varied from $8.0 \%$ to $0.6 \%$ and the discount rate was varied from $2 \%$ to $8 \%$.

\section{Conclusion}

An in hospital smoking cessation intervention delivered to a general population of adult patients was cost effective.

*Stevens VJ, Glasgow RE, Hollis JF, et al. Med Care 1993;31:65-72.

Smoking cessation intervention v usual care at 12 months $\dagger$

\begin{tabular}{lllll}
\hline Outcome & $\begin{array}{l}\text { Smoking cessation } \\
\text { intervention }\end{array}$ & $\begin{array}{l}\text { Usual } \\
\text { care }\end{array}$ & RRI $(95 \%$ CI) & NNT (CI) \\
\hline Abstinence & $13.5 \%$ & $9.2 \%$ & $47 \%(5.3$ to 105$)$ & $23(12$ to 174$)$
\end{tabular}

$\uparrow$ Abbreviations defined in glossary; RRI, CI, and NNT calculated from data in article.

Source of funding: National Cancer Institute.

For correspondence: Dr R T Meenan, Kaiser Permanente Center for Health Research, 3800 N Kaiser Center Drive, Portland, Oregon 97227-1098, USA. Fax +1 5033352424.

\section{Commentary}

Previous research has found nurse managed smoking cessation programmes for patients in hospital with myocardial infarction to be cost effective. ${ }^{1}$ The analysis by Meenan et al supports and extends these results. The lower cost effectiveness ratios associated with inpatient counselling programmes compared with outpatient educational programmes ${ }^{2}$ support the notion of a "teachable moment" when smokers are more likely to respond to a cessation message.

The original trial on which the economic analysis was based was not randomised. To avoid contamination, the hospital in which patients received the intervention was alternated each month. ${ }^{3}$ The original study took place in 2 hospitals that had smoke free policies requiring at least temporary cessation by patients who smoked. The results may not therefore be generalisable to other regions with differing societal mores and motivations to stop smoking.

Only $52 \%$ of patients provided samples for biochemical confirmation of abstinence*. Because of this low rate, it is possible that participants misreported their smoking status. The authors, however, used sensitivity analysis to estimate cost effectiveness even if the incremental quit rate fell from $4.3 \%$ to $0.6 \%$.

By combining published data on smoking related changes in life expectancy with overall life expectancy, the analysts could more accurately predict the long term effects of smoking cessation for individuals with differing smoking habits. The long term outcomes were discounted, which assumes that people place greater value on something they have today than something they will have in the future. The authors were able to investigate the impact of discounting using sensitivity analyses.

The results are relevant to nursing leaders in hospitals who are in a position to implement smoking cessation programmes, as well as staff nurses and outpatient clinicians who can reinforce the programmes.

Patricia Stone, RN, PhD

Nurse Practitioner, Harvard University Boston, Massachusetts, USA

*Data provided by author.

1 Krumholz HM, Cohen BJ, Tsevat J, et al. J Am Coll Cardiol 1993;22:1697-792.
Salkeld G, Phonovan P, Oldenburg B, et al. Salkeld G, Phongsavan P, Old

Health Policy 1997;41:105-19. 3 Stevens VJ, Glasgow RE, Hollis JF. Med Care
1993;31:65-72. 